\title{
Daidzein affects the stereological parameters of pituitary GH cell in orchidectomized adult
}

rat

\author{
S.Trifunović, V. Ajdžanović, B. Filipović, M. Miler, N. Ristić, I. Medigović, V. \\ Milosević \\ Institute for Biological Research «Siniša Stanković», University of Belgrade, Belgrade,Serbia
}

\section{Introduction}

*Soy isoflavonoids are plant phytoestrogens available as dietary supplements, and are increasingly advocated as a natural alternative to estrogen replacement therapy. The most significant isoflavones are genistein and daidzein. They are generally much less potent than estrogens, and act via similar mechanisms as estrogens.

*The somatotrophic system regulates somatic growth and development. The key mediator of somatotrophic system - growth hormone (GH) from pituitary GH cells, exerts direct and/or indirect effects on virtually every organ in the body.

*Estrogens have important imprinting effects on GH release during adult life.

*Being in mind that phytoestrogens have widespread effects on estrogen-sensitive cells, and that GH plays the key role in the control of the regulation of metabolism and physiological process, we hypothesized that phytoestrogen daidzein may have an influence on the stereological and biochemical parameters of pituitary GH cells.

\section{Results}

Stereological Analysis
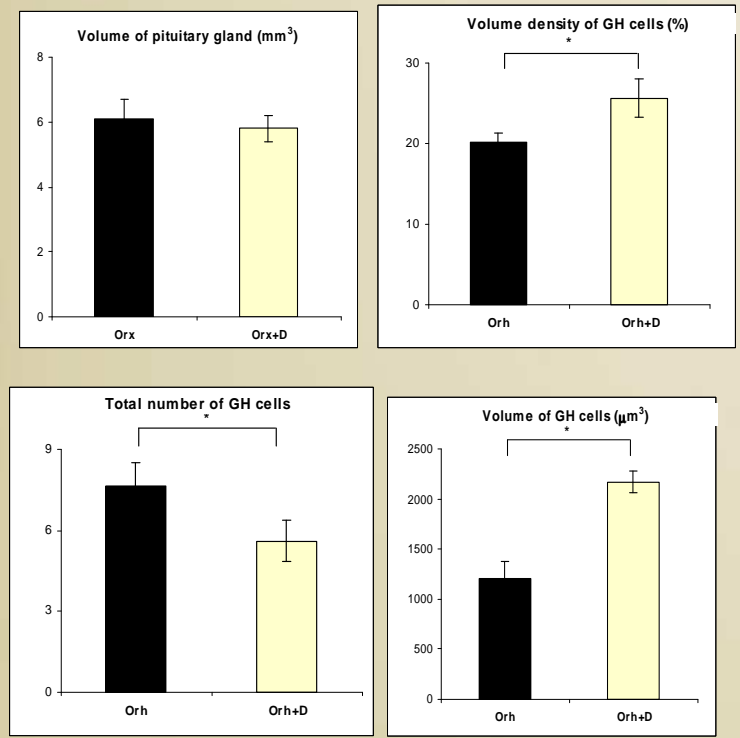

Hormonal Analysis -serum level of GH-

\begin{tabular}{|c|c|}
\hline Orx & $2.6 \pm 0.5 \mathrm{ng} / \mathrm{ml}$ \\
\hline Orx $+\mathrm{D}$ & $2.9 \pm 0.5 \mathrm{ng} / \mathrm{ml}$ \\
\hline
\end{tabular}

\section{Methods}

*The experiments were performed on adult, 2-month-old, male Wistar rats. Two weeks prior to the start of the experiment the rats were fed a soy-free diet. The experimental animals were bilaterally orchidectomized (Orx). Orchidectomy was performed with the goal of eliminating the endogenous gonadal steroids from the hormonal milieu.

*Adult Wistar rat were divided into two groups: orchidectomized rat subcutaneously (s.c.) treated with medium (absolute etanol and sterile olive oil mixture; Orx) and orchidectomized rats s.c. treated with daidzein in medium $(30 \mathrm{mg} / \mathrm{kg}$ b.w.; Orx+D). The groups of animals received the treatment during three weeks.

*Pituitary glands were excised. After embedding in Histowax serial sections of the pituitary ( $3 \mu \mathrm{m}$ thick) were obtained with a rotary microtome. Immunohisochemically labeled pituitary section were stereologically analysed, using newCast stereological software package.

*The circulating GH was determined biochemically. 